\title{
A 24-hour feasibility study of intraurethral valved catheter for bladder management in males with spinal cord injury
}

\author{
Bradley G. Orris, MD; ${ }^{1-2}$ Andrew E. Jahoda, MD; ${ }^{1-2}$ James S. Walter, PhD; ${ }^{2-3^{*}}$ Bernard N. Nemchausky, \\ MD; ${ }^{4}$ Rafael Wurzel, MD; ${ }^{5}$ Harvey D. Homan, PhD ${ }^{5}$ Sally Melloy, LPN; ${ }^{3}$ John S. Wheeler, MD ${ }^{1-2}$ \\ ${ }^{1}$ Department of Surgery, Edward Hines Jr Department of Veterans Affairs (VA) Hospital, Hines, IL; ${ }^{2}$ Department of \\ Urology, Loyola University Medical Center, Maywood, IL; Departments of ${ }^{3}$ Research and ${ }^{4}$ Spinal Cord Injury, \\ Edward Hines Jr VA Hospital, Hines, $I L ;{ }^{5}$ Urovalve, Inc, Newark, $N J$
}

\begin{abstract}
This feasibility study was conducted to evaluate design features of the novel intraurethral valved catheter, Surinate (Urovalve, Inc; Newark, New Jersey). The device extends from the bladder neck to just beyond the external sphincter and contains a valve that can be activated by an external magnet for bladder emptying. Five patients were recruited from the Edward Hines Jr Department of Veterans Affairs Hospital spinal cord injury population. We conducted cystometry and cystoscopy to evaluate the lower urinary tract. Then, the device was inserted for 24 hours with careful monitoring. The catheter was removed from the first patient because he developed autonomic dysreflexia during implantation. The next four patients used the catheter overnight and tolerated it well: one with independent use and two with increased abdominal pressure. Emptying time was $208+/-99 \mathrm{~s}$, residual was $42+/-33 \mathrm{~mL}$, and the first-stream flow rate was $1.8+/-0.7 \mathrm{~mL} / \mathrm{s}$. The safety tether was used in three patients because the extraction device did not work. Results showed effective implantation and stability of the device in the urethra. However, objectives for use and extraction were not met. This feasibility study provided important information that will help guide design improvements for the intraurethral valved catheter.
\end{abstract}

Key words: catheterization, cystometry, cystoscopy, intraurethral valved catheter, neurogenic bladder, rehabilitation, spinal cord injury, urinary incontinence, urinary retention, UTI.

\section{INTRODUCTION}

The most common methods of bladder management following spinal cord injury (SCI) include indwelling Foley catheters, external condom catheters, and clean intermittent catheterization (CIC) [1-6]. CIC is considered the standard of care because long-term outcomes with this method have been shown to be better than with the other methods. However, all the methods have limitations for some patients who may have problems in the areas of urinary tract infections (UTIs), urethral trauma, and difficulty with the use of anticholinergic medications as part of some of the methods [4,7-8]. Various surgical procedures have been developed to improve upon methods of bladder management, such as sacral nerve root stimulation, urinary diversion, and suprapubic catheters, but all the surgical methods are invasive and have limitations [9].

This study evaluated the feasibility of a new type of internal urethral catheter that spans from the bladder neck to just distal to the striated urethral sphincter and contains

Abbreviations: $\mathrm{CIC}=$ clean intermittent catheterization, $\mathrm{SCI}$ = spinal cord injury, TRUS $=$ transrectal ultrasound, UTI = urinary tract infection.

*Address all correspondence to James S. Walter, PhD; Edward Hines Jr VA Hospital (151), Research Service, Hines, IL 60141; 708-202-5805; fax: 708-202-2319.

Email: james.walter@med.va.gov

DOI: 10.1682/JRRD.2007.07.0112 
a magnetically actuated valve that allows for the controlled flow of urine. This intraurethral valved catheter is the Surinate ${ }^{\circledR}$ (Urovalve, Inc; Newark, New Jersey) (Figures 1-2). The device was designed to provide the following features: (1) allow bladder emptying by the patient through the use of a magnetic valve and (2) avoid having a catheter pass through the urethral meatus, a known risk for UTI. The Ontario Neurotrauma Foundation (http://www.onf.org) has highlighted this area of research for funding of new approaches for SCI bladder care [10].

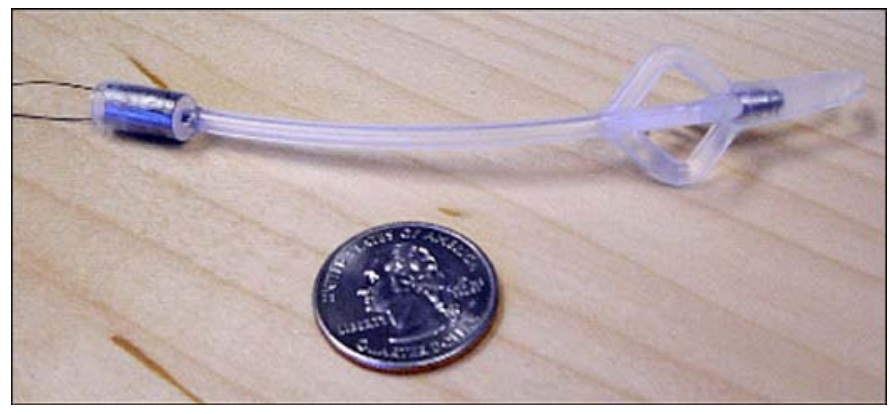

Figure 1.

Intraurethral valved catheter, Surinate. Malecot tip is shown in upper right corner and magnetic valve in lower left with safety tether attached.

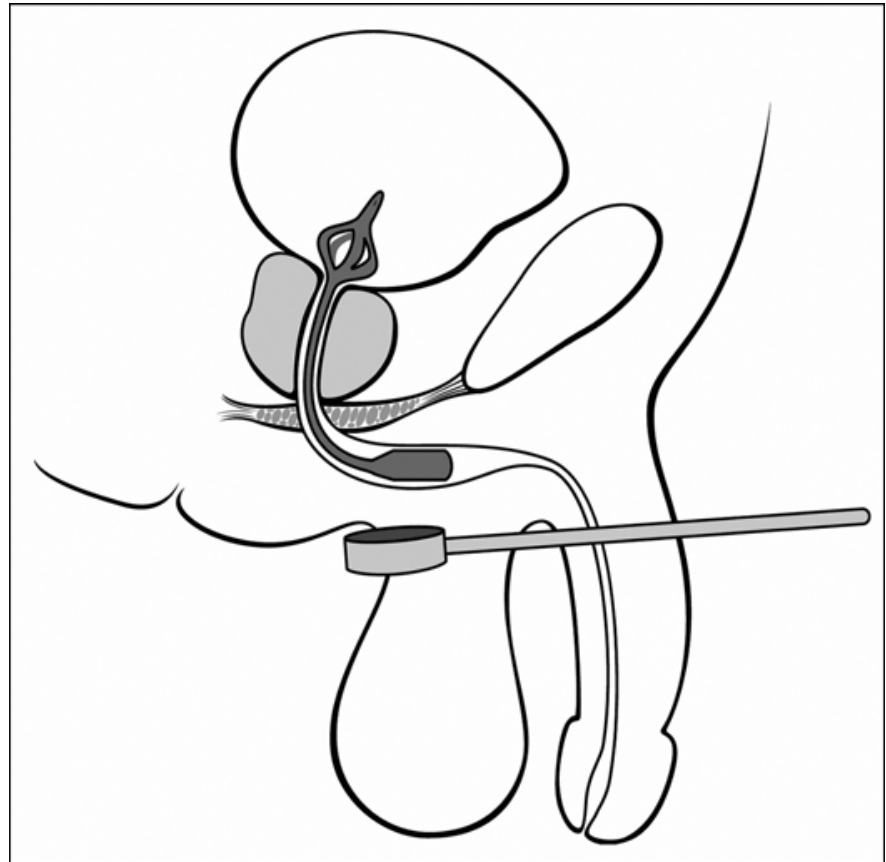

Figure 2.

Intraurethral valved catheter, Surinate, with activator magnet in position for bladder emptying.
The objectives of this 24-hour feasibility study were to (1) assess insertion and extraction instruments and methods; (2) determine whether the device migrates from the position of original placement; (3) assess function and mechanical reliability of the device for bladder emptying based on measurement of urine flow rate, residual volume, and ease of operation by the patient; and (4) assess safety and tolerability during the period the device is in the urethra.

\section{MATERIALS AND METHODS}

Five adult male patients with complete or incomplete third thoracic or lower SCI, a neurogenic bladder, and a documented history of chronic urinary retention or incontinence were recruited from the SCI service for this prospective study (see Table 1 for detailed medical history). This study was conducted under the approval of the Edward Hines Jr Department of Veterans Affairs Hospital Investigational Review Board, with investigational device exemption from the U.S. Food and Drug Administration.

Following enrollment and informed consent, we screened all patients with medical history, physical examination, and urine dipstick analysis to evaluate for UTI. Additionally, all patients were given a 4-day course of a prophylactic oral antibiotic beginning on the morning of the study. Adverse events are reported as well as function and any difficulty with the device.

\section{Cystometry}

Next, we conducted cystometry with a rectal balloon and recorded abdominal pressure with a dual lumen urodynamic catheter (model DLC-6D, 6 French, Life-Tech, Inc; Stafford, Texas) in the bladder. Vesical pressure is an important pressure to report because it is the total pressure that promotes urine flow. Vesical pressure is defined as detrusor pressure (pressure due to the bladder wall) plus abdominal pressure; it is the pressure recorded in the bladder after a hydrostatic zero pressure is set external to the patient and at the top of the suprapubic bone. We can obtain detrusor pressures by subtracting abdominal pressure from vesical pressure. Filling was conducted at $50 \mathrm{~mL} / \mathrm{min}$ to a volume of $300 \mathrm{~mL}$ or until a detrusor pressure of $50 \mathrm{cmH}_{2} \mathrm{O}$. A filling volume of 150 $\mathrm{mL}$ with a detrusor pressure of $50 \mathrm{cmH}_{2} \mathrm{O}$ or lower was required for continuation in the study. During cystometry, the patient's head was elevated on average $20^{\circ}$. One 
Table 1.

Patient medical history.

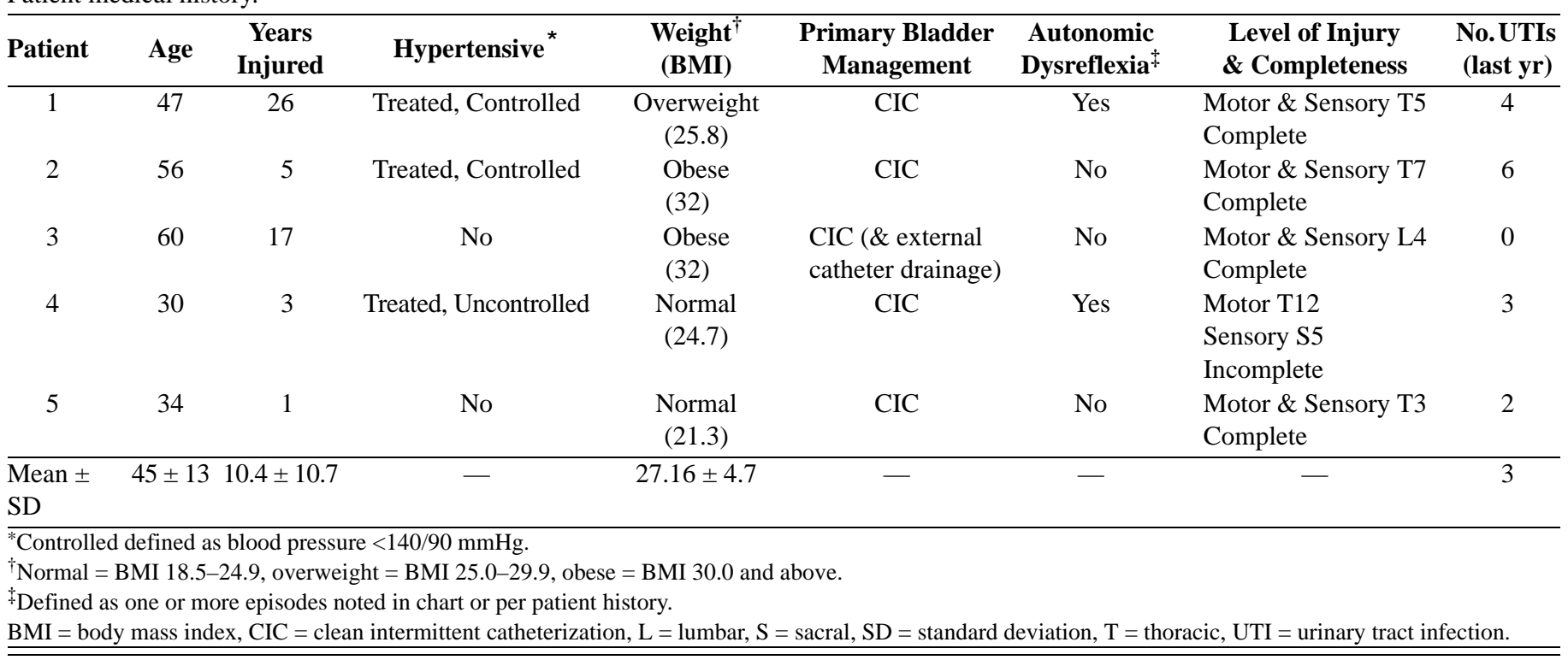

patient was prone $\left(0^{\circ}\right)$ because of recent surgery on a decubitus ulcer. Blood pressure and pulse were monitored throughout the entire procedure.

\section{Cystoscopy}

Following cystometry, we performed cystoscopy using a 15 French flexible cystoscope to assess the lower urinary tract and measure the length of the urethra. Measurements were taken from the bladder neck to the urethral meatus as well as from the external sphincter to the urethral meatus. We subtracted these values to determine the length of the urethra from the bladder neck to the external sphincter and to determine the proper size device. The implantable device was available in 60 and $80 \mathrm{~mm}$ lengths. Criteria for determining the device length to insert changed during the study. Initially we inserted the shortest one that could extend beyond the measured length. But, we changed our protocol after our initial experience to only implant the $80 \mathrm{~mm}$ length.

\section{Insertion and Use of Surinate}

We employed a specially designed mandarin stylet that engaged the tip of the catheter and collapsed the malecot wings during insertion into the bladder at $1 \mathrm{~cm}$ from the bladder neck (Figure 2). The previously described urethral measurements were used for insertion distance. One important objective was determining whether the device could be placed correctly. Position in the bladder and urethra was determined by transrectal ultrasound
(TRUS) of the malecot in the bladder. Once the device was properly positioned, we disengaged the insertion stylet to expand the malecot wings and inserted a nylon 2,0 tether that extended from the urethra to aid in removal of the catheter if any difficulties arose with the extraction device.

We activated the valve by placing a magnet in the patient's perineum and collected the urine in a handheld urinal, a bedside urinal, or a cup (Figure 2). We determined three different flow rates (ratio of volume collected to collection time). First, we determined the average flow rate of the first stream of urine with the first magnet activation. This average did not include time searching with the magnet before bladder draining started. Second, we calculated the peak flow rate. For this rate, we placed a cup in the urine stream for collection once the peak flow rate was observed. The collection period for this rate was 10 or $20 \mathrm{~s}$. Third, we calculated an average for the entire procedure and included the total volume voided and the total time taken to empty the bladder, including time searching with the magnet. This calculation did not include the short rest periods between attempts to empty the bladder with the magnet. We used bladder ultrasound to determine initial bladder volume before use of the magnet and the residual after repeated uses of the magnet. Incontinence between attempts to use the magnet for emptying was measured by the increased weight of the patient's diaper. Blood pressure and pulse were monitored before and after each bladder draining. 
Bladder volume was also monitored every 1 to 2 hours with ultrasound.

The catheter was left in place for 24 hours. During this time, the patients were encouraged to engage in their typical daily activities, but activity was limited by the frequent ultrasound scans and bladder emptying procedures. Several objectives were assessed during this time including function, mechanical reliability, and safety. Function was assessed by bladder emptying with residual volume less than $100 \mathrm{~mL}$, bladder emptying without having to add additional pressure such as abdominal straining or abdominal pushing, and a flow rate $>3 \mathrm{~mL} / \mathrm{s}$ (which reduces the amount of time required to empty the bladder). Mechanical reliability was further assessed by determining whether we could repeatedly empty the bladder with application of the magnet. Device migration within the urethra was also a factor in mechanical reliability. Migration was determined by determining whether the magnet location for opening the catheter valve moved during the time when the device was in place. At the end of the study, we attempted to remove the catheter using an extraction device that consisted of a round-end rod. This device was passed into the urethra to engage the distal end of the catheter, which could then be used to pull the catheter out. Thus, an objective for this study was to determine whether the extraction device could engage the catheter and be used to pull the catheter out. If the extraction device was not successful, the catheter was removed using the safety tether. Following extraction, the patients were asked a global question about their willingness to try the device again in the future if another study were available, and they were given the choice of a simple yes or no answer. They were also followed up by telephone follow-up for 1 week to assess any adverse events.

\section{RESULTS}

Initial cystometry testing demonstrated that all patients met the entry criteria for enrollment in the study (Table 2). The $20^{\circ}$ to $30^{\circ}$ tilt in the first four patients produced an abdominal pressure of 8 to $30 \mathrm{cmH}_{2} \mathrm{O}$ that was reflected in the vesical pressure. However, the detrusor pressures in the first four patients were all close to zero at the start of filling. The fifth patient that was prone had nearly zero abdominal and vesical pressures. Four patients had filling volumes to $300 \mathrm{~mL}$ with detrusor pressures below $50 \mathrm{cmH}_{2} \mathrm{O}$; however, one of these patients did have a detrusor pressure of $40 \mathrm{cmH}_{2} \mathrm{O}$ at the $300 \mathrm{~mL}$ volume. Patient two had the cystometry stopped at $227 \mathrm{~mL}$ because his detrusor pressure reached $50 \mathrm{cmH}_{2} \mathrm{O}$. This patient's first detrusor contraction was at $190 \mathrm{~mL}$. Abdominal pressure remained relatively constant in all patients, with an average of $20 \pm 11 \mathrm{cmH}_{2} \mathrm{O}$ at the end of filling (all data presented as mean \pm standard deviation).

Cystoscopy did not reveal any significant pathology in any patient. The length of the proximal urethra including the bladder neck, prostatic urethra, and external sphincter was $4.0 \pm 2.3 \mathrm{~cm}$, and the length of the urethra from the meatus to the bladder neck (with the penis on mild stretch) was $21.1 \pm 0.6 \mathrm{~cm}$.

Insertion of the catheter was problematic in the first patient, who developed autonomic dysreflexia. Initially, the catheter was not inserted all the way into the bladder and, then during a second attempt, it was inserted too far

Table 2.

Cystometric results prior to use of Surinate.

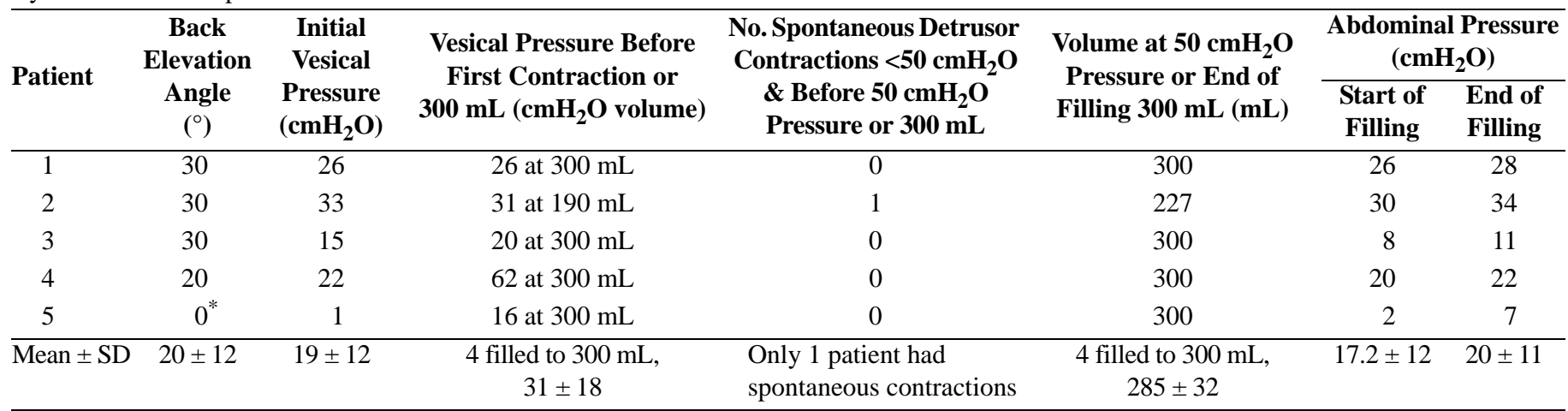

${ }^{*}$ Patient 5 was lying flat $\left(0^{\circ}\right)$ because of concern about back ulcer that was healed. 
into the bladder. We avoided this problem in subsequent patients by better using the urethral length measurements to judge how far to insert the catheter. Insertion based on cystoscopic measures of the length to the bladder neck and length from the neck to the external sphincter (for the device size) worked well in the last four patients. The valve was palpable in the perineum in two patients, with obesity being a primary interfering factor in the remaining patients. TRUS confirmed placement by displaying the location of the malecot and catheter in the bladder.

The valve location in the urethra just proximal to the scrotal perineal junction was effective and was relatively easy for the urologist or nurse-investigator to activate with the external magnet. However, only one patient was able to use the device to empty the bladder without any assistance. Activating the valve was more difficult when the valve was deeper in the perineum, as in patients one through three. These three patients had difficulty using the device independently. The device worked better when patients were sitting up in a wheelchair than when patients were leaning back in bed. The last two patients did not experience any spontaneous urine flow with activation of the valve until strong Valsalva or credê maneuvers were applied. Two patients experienced mild incontinence between uses. Incontinence volumes were low compared with voided volumes. Migration of the device was not noted in any of the patients during the 24-hour trial period.

The four patients with the device implanted for 20 to 24 hours had their bladders emptied an average of nine times with the device (Table 3). The average total time to empty the bladder, including time used to position the magnet, was $208 \pm 99$ s. The total voided volume averaged $242 \pm 32 \mathrm{~mL}$, with a mean residual of $42 \pm 33 \mathrm{~mL}$. Average flow rates for the first stream ranged from 1.0 to $2.4 \mathrm{~mL} / \mathrm{s}$, with an overall average of $1.8 \pm 0.7 \mathrm{~mL} / \mathrm{s}$.

Peak flow rates using the cup method averaged $4.5 \pm$ $3.6 \mathrm{~mL} / \mathrm{s}$ (range 1.1-9.3 mL/s). Patient number three had a high peak flow of $9.3 \mathrm{~mL} / \mathrm{s}$; however, this high rate was likely due to a spontaneous bladder contraction with some flow around the catheter as the flow did not stop when the magnet was removed. Patient four also had a high peak flow rate when a strong Valsalva was conducted, but this flow was through the catheter as removal of the magnet stopped the flow.

Criteria for determining the length of the device implanted changed during the course of the study. The $60 \mathrm{~mm}$ length was chosen for the first two patients as this length was sufficient based on cystoscopy measures. However, because some difficulties were encountered with insertion or use of the device, for the final three patients, we only implanted the $80 \mathrm{~mm}$ length. This longer length also facilitated locating the valve closer to the scrotal sac, an area of the urethra that is closer to the skin and thus easier for the magnet to activate.

The extraction device was used successfully in one patient for removal of the catheter. It was also engaged and used to reposition the catheter in a second patient. However, the extraction device did not work to remove the catheter in three of the four patients. The tether worked effectively for removal in these three patients.

Table 3.

Overall urodynamic responses of use of Surinate for bladder emptying. ${ }^{*}$

\begin{tabular}{|c|c|c|c|c|c|c|c|c|}
\hline Patient & Used & $\begin{array}{l}\text { No. Uses to Empty } \\
\text { Bladder During } \\
\text { Test Period }^{\dagger}\end{array}$ & $\begin{array}{c}\text { Total Time } \\
\text { to Empty (s) }\end{array}$ & $\begin{array}{l}\text { Total } \\
\text { Measured } \\
\text { Voided } \\
\text { Volume }(\mathrm{mL})\end{array}$ & $\begin{array}{l}\text { Residual by } \\
\text { Ultrasound } \\
\text { (mL) }\end{array}$ & $\begin{array}{l}\text { Incontinence } \\
\text { Between Uses } \\
(\mathrm{mL})^{\S}\end{array}$ & $\begin{array}{c}\text { First Stream } \\
\text { Flow Rate } \\
\text { (mL/s) }\end{array}$ & $\begin{array}{c}\text { Peak Flow } \\
\text { Rate }(\mathrm{mL} / \mathrm{s})^{\uparrow}\end{array}$ \\
\hline 1 & No & - & - & - & - & - & - & - \\
\hline 2 & Yes & 8 & 150 & 194 & 18 & 119 & 2.4 & 2.5 \\
\hline 3 & Yes & 13 & 112 & 257 & 29 & 12 & 2.3 & 9.3 \\
\hline 5 & Yes & 7 & 336 & 251 & 91 & 0 & 1.0 & 1.1 \\
\hline Mean \pm SD & - & $9 \pm 3$ & $208 \pm 99$ & $242 \pm 32$ & $42 \pm 33$ & $33 \pm 58$ & $1.8 \pm 0.7$ & $4.5 \pm 3.6$ \\
\hline \multicolumn{9}{|c|}{$\begin{array}{l}{ }^{*} \text { Each value is expressed as average over entire period that each individual patient had valve implanted. } \\
{ }^{\dagger} \text { Average time that catheter was implanted was } 21.7 \pm 1.7 \text { hours. } \\
{ }^{\ddagger} \text { Average time per use including searching with magnet and voiding time (rest periods excluded). } \\
{ }^{\S} \text { Part of majority of measured incontinence occurred during use of Surinate. } \\
\text { "Rate measured by volume in cup during } 10 \text { or } 20 \mathrm{~s} \text { stream. } \\
\text { SD = standard deviation. }\end{array}$} \\
\hline
\end{tabular}


After the first patient, no serious or unanticipated events occurred. Slightly elevated blood pressure during the 24-hour period was noted in patient two, but no intervention was required. This patient was being treated for essential hypertension, and the condition may have contributed to the elevated pressure in this study. None of the patients reported any pain with use of the device. All the patients answered yes when asked if they would like to try the device again in the future if another study of the device were being conducted.

\section{DISCUSSION}

Presently, the majority of patients with SCI, multiple sclerosis, and other neurological impairment who have bladder impairment use CIC to empty their bladders. Other methods are external and Foley catheters [1-6]. CIC has become the standard of care because it is associated with low rates of adverse events; however, some patients have complications. For example, in this study, patients using CIC reported two to six UTIs a year $[4,7]$. Therefore, continuing to investigate new methods of bladder management is important.

Several "intraurethral catheters" have been developed for treatment of benign prostatic hypertrophy or for temporary placement after minimally invasive prostate surgery as an alternative to standard Foley catheters [1115]. These catheters share common features with the Surinate; they extend from the bladder neck to the proximal urethra and have retention designs to prevent migration. These devices, however, use the patients' own external urethral sphincter for urinary control rather than a valve mechanism. In addition, none of these devices has become commercially available in the United States. Thus, this report should be of great interest to the many groups that are working in this important area. Another alternative is urethral stents as more permanent urethral implants [16-17].

The Surinate is a silicone rubber catheter that has a miniature magnetic proximity valve (a fluid flow valve that opens when a magnet is placed nearby) at its outflow end. The proximal end has a malecot tip to prevent migration. When the catheter is inserted into the urethra, it bridges the bladder neck, prostate, and external sphincter and provides a valve connection between the bladder and the bulbous urethra. The valve is opened by a small, handheld magnet placed against the perineum. Valve closure is spontaneous when the handheld magnet is withdrawn from the body. The device will be designed as an indwelling catheter to be changed on a monthly basis. Magnetcontrolled urine flow was established in the last four patients.

Some aspects of this device worked in this study. Placement using measurement of the urethra with cystoscopy was effective, except for the first patient, when measuring methods were still being developed. Although TRUS confirmed placement of the device, we do not think that TRUS would be required if routine clinical application of a device like this were to occur. Migration of the device was not a problem; it stayed where it was implanted for 24 hours. Although the extraction device did not work well, the tether worked for removal. The extraction device had a rounded end so that even though it was a blind attempt to engage the device in the urethra for extraction, it did not appear to cause any urethral trauma. An effective extraction device is an important area of redesign.

Problems were identified in the last four patients that will require design changes. Patients had difficulty using the device independently. Some could not hold the magnet in place and hold a urinal at the same time. Low flow rates need to be increased in future devices. Emptying was improved in the upright position in some patients. We believe that this improvement was due to higher abdominal pressures (pressures not measured) when the patient was in the more upright position. Passive abdominal pressure was not adequate for effective bladder emptying in two of the four patients. This finding indicates a problem with the device, possibly kinking of the tubing within the urethra. Alternatively, the valve may have been too small to allow for adequate flow. In vitro studies demonstrated a flow rate through the valve of $2.9 \pm 0.1 \mathrm{~mL}$ at $50 \mathrm{cmH}_{2} \mathrm{O}$ (data from Urovalve, Inc). The problems encountered during this feasibility study should be addressed in design changes to the Surinate prior to future studies.

The patient's urodynamic status is not expected to be an important factor for functioning of the device. For example, the bladder hyperreflexia in patient two or the noncompliant bladder in patient four should both allow for urine flow when the valve is opened with the magnet. However, as the valve is normally closed when not activated by the magnet, we will need to conduct urodynamics to assess at what volume bladder contractions occur and determine the frequency of device use to avoid spontaneous bladder contractions. Encouragingly, the use of 
the $80 \mathrm{~mm}$-long device resulted in the valve location under the scrotum, a location for easy magnet activation.

Limitations of the study include the short time period of 24 hours of testing. In addition, the use of antibiotics by the patients means that possible effects of the device on UTI rates could not be studied. Future studies should include additional urodynamic measures. Bladder pressure cannot be recorded as the Surinate prevents placement of another catheter through the urethra into the bladder for pressure recording. Rectal pressure could be recorded and would add an important measure of abdominal pressures. The Ontario Neurotrauma Foundation has given this area of research a high priority for the goal of improved SCI bladder management [10].

\section{CONCLUSIONS}

Results showed effective implantation and stability of the device in the urethra. However, objectives for use of the device and extraction were not met. Thus, we obtained important information to guide design improvements for the intraurethral valved catheter. An improved device could warrant further investigation to meet the stated objectives such as independent patient use with an adequate urine flow as well as reliable device implantation and extraction.

\section{ACKNOWLEDGMENTS}

We acknowledge Jean Seidel for editorial assistance.

This material was based on work supported by Urovalve, Inc; Newark, New Jersey, and in part by the National Institutes of Health, National Institute of Child Health and Human Development (grant 5R44HD039566-03).

\section{REFERENCES}

1. Jamil F. Towards a catheter free status in neurogenic bladder dysfunction: A review of bladder management options in spinal cord injury (SCI). Spinal Cord. 2001;39(7):35561.

[PMID: 11464308]

2. Weld KJ, Wall BM, Mangold TA, Steere EL, Dmochowski RR. Influences on renal function in chronic spinal cord injured patients. J Urol. 2000;164(5):1490-93.

[PMID: 11025689]
3. Ord J, Lunn D, Reynard J. Bladder management and risk of bladder stone formation in spinal cord injured patients. J Urol. 2003;170(5):1734-37. [PMID: 14532765]

4. Stickler DJ, Zimakoff J. Complications of urinary tract infections associated with devices used for long-term bladder management. J Hosp Infect. 1994;28(3):177-94. [PMID: 7852732]

5. Roberts JA, Fussell EN, Kaack MB. Bacterial adherence to urethral catheters. J Urol. 1990;144(2 Pt 1):264-69.

[PMID: 2115595]

6. Gerridzen RG, Thijssen AM, Dehoux E. Risk factors for upper tract deterioration in chronic spinal cord injury patients. J Urol. 1992;147(2):416-18. [PMID: 1732606]

7. Stover SL, DeLisa JA, Whiteneck GG. Spinal cord injury: Clinical outcomes from the model systems. Gaithersburg (MD): Aspen Publications; 1995. p. 250.

8. McKinley WO, Jackson AB, Cardenas DD, DeVivo MJ. Long-term medical complications after traumatic spinal cord injury: A regional model systems analysis. Arch Phys Med Rehabil. 1999;80(11):1402-10. [PMID: 10569434$]$

9. Zommick JN, Simoneau AR, Skinner DG, Ginsberg DA. Continent lower urinary tract reconstruction in the cervical spinal cord injured population. J Urol. 2003;169(6):2184-87. [PMID: 12771745]

10. Hayes KC, Bassett-Spiers K, Das R, Ethans KD, Kagan C, Kramer JL, Linsenmeyer T, Moore KN, Razvi H, Reid G, Walter JS, Wilson JW. Research priorities for urological care following spinal cord injury: Recommendations of an expert panel. Can J Urol. 2007;14(1):3416-23. [PMID: 17324320]

11. Madjar S, Sabo E, Halachmi S, Wald M, Issaq E, Moskowitz B, Beyar M, Nativ O. A remote controlled intraurethral insert for artificial voiding: A new concept for treating women with voiding dysfunction. J Urol. 1999;161(3): 895-98. [PMID: 10022709]

12. Nativ O, Moskowitz B, Issaq E, Condrea A, Kastin A, Halachmi S, Burbara J, Madjar S, Beyar M. A new intraurethral sphincter prosthesis with a self contained urinary pump. ASAIO J. 1997;43(3):197-203. [PMID: 9152491]

13. Corujo M, Badlani GH, Regan JB, Lynch JH, Tomera K, Schmidt R, Calvosa C, Ramsey E, Lightner DJ, Barrett DM. A new temporary catheter (ContiCath) for the treatment of temporary, reversible, postoperative urinary retention. Urology. 1999;53(6):1104-7. [PMID: 10367835]

14. Djavan B, Fakhari M, Shariat S, Ghawidel K, Marberger M. A novel intraurethral prostatic bridge catheter for prevention of temporary prostatic obstruction following high energy transurethral microwave thermotherapy in patients with benign prostatic hyperplasia. J Urol. 1999;161(1): 144-51. [PMID: 10037387]

15. Nissenkorn I, Slutzker D, Shalev M. Use of an intraurethral catheter instead of a Foley catheter after laser treatment of benign prostatic hyperplasia. Eur Urol. 1996;29(3):341-44. [PMID: 8740021] 
16. Chancellor MB, Gajewski J, Ackman CF, Appell RA, Bennett J, Binard J, Boone TB, Chetner MP, Crewalk JA, Defalco A, Foote J, Green B, Juma S, Jung SY, Linsenmeyer TA, MacMillan R, Mayo M, Ozawa H, Roehrborn CG, Shenot PJ, Stone A, Vazquez A, Killorin W, Rivas DA. Long-term follow-up of the North American multi-center UroLume trial for the treatment of external detrusor-sphincter dyssynergia. J Urol. 1999;161(5):1545-50.

[PMID: 10210393]
17. Corica AP, Larson BT, Sagaz A, Corica AG, Larson TR. A novel temporary prostatic stent for the relief of prostatic urethral obstruction. BJU Int. 2004;93(3):346-48.

[PMID: 14764134]

Submitted for publication July 24, 2007. Accepted in revised form October 23, 2007. 